\title{
Palm Kernel Oil
}

National Cancer Institute

\section{Source}

National Cancer Institute. Palm Kernel Oil. NCI Thesaurus. Code C84039.

The edible oil extracted from the kernels of the oil palm, Elaeis guineensis. Palm kernel oil is commonly used as a commercial cooking oil due to its stability at high temperatures. 